\title{
Cronotopos y estereotipos de la ficción publicitaria. Un análisis sobre la identificación del receptor con el relato publicitario
}

\author{
Javier GARCÍA LÓPEZ \\ Universidad a Distancia de Madrid \\ javier.garcia@udima.es \\ Pedro A. Hellín OrtuÑo \\ Universidad de Murcia \\ phellin@um.es
}

\begin{abstract}
Resumen:
En el relato publicitario hay dos componentes principales con los que el receptor se identifica. Son el cronotopo y los personajes estereotipados. El objetivo del presente trabajo es analizar cómo estas dos categorías narrativas imponen límites en el proceso de decodificación por parte de la audiencia. Para ello, desarrollamos un análisis de contenido de 612 anuncios televisivos (2009-2013). Los resultados nos muestran que escenarios y relaciones representados ofrecen al receptor esperanzas de una vida mejor; ofrecen un mundo de ficción que permite a los individuos identificarse con el sueño de experiencias que mejoran sus condiciones actuales. Aunque estas nuevas experiencias solo son posibles mediante el consumo de los objetos publicitados.
\end{abstract}

Palabras clave: publicidad televisiva; cronotopo; personajes; estereotipos

\section{Chronotopes and stereotypes in advertising fiction. An analysis of the identification of the receptor with the advertising story}

\begin{abstract}
:
In the advertising story there are two main components to the receiver is identified. They are the chronotope and stereotypical characters. The aim of this paper is to analyze how these narrative categories impose limits on the advertising text audience's decoding. For this purpose we develop a content analysis of 612 television adverts (2009-2013). The research results show that the relations and scenes represented offer the receiver hopes of a better life; they offer a fiction world that allows individuals to identify with the dream of experiences that improve their current conditions. However, these new experiences are only possible through the use of advertised objects.
\end{abstract}

Key words: TV Advertising; chronotope; characters; stereotypes

\section{Referencia normalizada:}

García López, J. y Hellín Ortuño, P.A. (2014): Cronotopos y estereotipos de la ficción publicitaria. Un análisis sobre la identificación del receptor con el relato publicitario Historia y Comunicación Social. Vol. 19. Núm. Especial Enero. Págs. 759-769.

Sumario: 1. Introducción; 2. La cultura publicitaria como representación de la cultura dominante; 3. Metodología; 4. Resultados y discusión. Cronotopos y estereotipos, recursos narrativos para la identificación; 5. Conclusiones; 6. Bibliografía 


\section{Introducción}

El mito de la felicidad ordena las vidas de los individuos en las sociedades actuales. Gran parte de las actividades que desarrollamos de manera cotidiana están encaminadas hacia la consecución de la felicidad. Sin embargo, y por ese motivo hablamos de mito, la felicidad raramente se materializa o es tan volátil que se desvanece y únicamente nos queda el recuerdo de momentos felices que constantemente deseamos repetir o experimentar por primera vez. La publicidad se aprovecha de esta dinámica humana y nos muestra los cielos, los paraísos, los nirvanas posibles. El discurso publicitario se fundamenta en el deseo constante de los individuos de alcanzar momentos de felicidad que, atendiendo al sistema en el que funcionamos, se vehiculizan a través de objetos que se compran y que se venden; los objetos publicitados. A través de los relatos de la publicidad, las personas sustentan su posición ideológica que, en la mayoría de casos, coincide con el patrón ideológico dominante (Kates y Shaw-Garlock, 1999: 33-49). Así que las narraciones ficcionales de la publicidad deben analizarse como una herramienta ideológica de las instituciones sociales (Aaker, Bartra y Myers, 1996). Porque, como apostilla Geertz (2003: 179), "la ideología suministra una salida simbólica a las agitaciones emocionales generadas por el desequilibrio social" y ello sirve a los emisores comerciales para persuadir al receptor y solazarlo hacia su mundo de placer. Por tanto, hablamos de un modo de comunicación comercial con un carácter intencionalmente persuasivo y deliberadamente socializador, en tanto que la publicidad consigue tornar su ficción dirigida al individuo en experiencias comunes y simbólicamente compartidas (Lull, 2009: 22).

Los modos narrativos de la publicidad para conseguir persuadir al receptor son múltiples. Si bien, el relato gráfico o audiovisual debe atrapar al individuo mediante un juego de relaciones entre los componentes del lenguaje publicitario que son, a la vez, las representaciones de los componentes dramáticos del lenguaje literario de la vida. En ese lenguaje adquieren importancia las personas, sus relaciones y el espacio en el que suceden esas relaciones, como ocurre en cualquier novela o película cinematográfica.

El objetivo principal del presente trabajo es identificar dichos componentes y relaciones en el relato ficcional de la publicidad y observar qué posibles efectos pueden tener en la interpretación potencial del receptor. Para ello, nos vamos a centrar en una muestra de publicidad audiovisual española, a través de la cual vamos a analizar principalmente qué personajes y escenarios se proponen y qué tipo de relaciones entre ellos se ofrecen para alcanzar la persuasión.

\section{La cultura publicitaria como representación de la cultura dominante}

Las corporaciones utilizan el discurso de la publicidad para posicionarse de una manera activa con el propósito de conectar con las audiencias como si de una relación personal se tratase. Los textos publicitarios se comunican con el individuo, debido 
a que la comunicación publicitaria está cargada de un potente individualismo (Hirschman, 2003: 21). No quiere decir esto que las personas no tengan en cuenta a los demás miembros de la sociedad o del grupo en el que viven. Al contrario, esa fuerza individualista se transfiere en una comunicación de tú a tú entre el relato publicitario y su receptor con el objetivo de que este último sienta la presión social para pensar o actuar de un modo determinado.

Además, los objetos publicitados por las empresas e instituciones adquieren un peso conceptual que atiende a la pauta simbólica, ideológica, de cada cultura. Esto ocurre incluso en ciertos lugares en los que hasta hace muy poco tiempo no se pensaba que el sistema de consumo occidental pudiera tener un gran impacto (Lin, 2001). Así, la publicidad se convierte en un medio de transmisión de valores culturales, bien asumiendo la carga axiológica en el relato de ficción representado por medio de los distintos componentes de la narración, bien proyectando dichos valores hacia el receptor. Por consiguiente, la publicidad grava la interpretación potencial de los individuos mediante un sistema discursivo con límites ideológicos, que concuerdan con las fronteras simbólicas y de actuación que permite el sistema social hegemónico (Wernick, 1983; 1994).

El hecho de que la publicidad y su discurso sean componentes culturales o cultura en sí mismos puede resultar evidente. Las investigaciones que vinculan publicidad y cultura así lo determinan (Williams, 1993). Como explica Eguizábal, "decir que la publicidad es cultura, resulta una obviedad. Todo es cultura, decía Roland Barthes; el tema reside en que es eficaz en cuanto es cultura y eso la sitúa más allá de otras obviedades mayores" (2007: 325). La publicidad es una herramienta de ciertas instituciones sociales, quienes la utilizan para conseguir sus objetivos. Estos objetivos suelen ser la consecución de beneficios económicos o la adhesión a una perspectiva de pensamiento o de acción. Como argumenta Jhally (1987: 1), la publicidad "ejerce mayor influencia en la sociedad moderna en el ejercicio de la socialización". Las narraciones de la publicidad influyen en la manera en la que la sociedad contemporánea construye su pensamiento imperante y en cómo forjan los individuos sus identidades individuales y colectivas. Según San Nicolás, el discurso de la publicidad:

Puede considerarse como una forma de "producción industrializada de realidad", consiguiendo propagar dentro de los colectivos sociales los criterios y pautas de actuación de las culturas dominantes -institucionales y/o corporativas-, en un esfuerzo por trazar una clara influencia sobre la conducta y por conseguir determinar las representaciones sociales de los diferentes públicos (2003: 18).

No obstante, la cultura hegemónica configura los relatos de la publicidad y esta ayuda a reorganizar y difundir dicha cultura, mediante una limitación interpretativa impuesta en la emisión (McQuarrie, 1999: 38). Y entendemos cultura en el sentido de Harris, para quien la cultura son " tradiciones de pensamiento y conductas aprendidas y socialmente adquiridas que aparecen en las sociedades humanas" (2007: 141). Así que la cultura son estilos de vida que la mayor parte de individuos de una sociedad comparte. Además, esos estilos de vida, compuestos por relaciones sociales (personajes) y por espacios concretos (escenarios) imaginados son objetos de veneración 
y de deseo. La publicidad es, por tanto, un instrumento cultural. A través de ella, las personas pueden observar las tendencias sociales por las que deben regirse $y$, al mismo tiempo, los individuos ven sus vidas proyectadas en los relatos de ficción de la publicidad. Se trata de un juego de ambivalencias simbólicas que ayuda a la cultura preeminente a perpetuarse.

Todo este mecanismo es posible debido a que la publicidad, como hecho cultural, da lugar a una pauta de significación coherente con las imposiciones conductuales de la sociedad del momento. La cultura y todas sus manifestaciones implican un discurso dividido en un estrato superficial o fácilmente entendible y otro discurso interior que se diluye. Así lo muestra Geertz:

Creyendo con Max Weber que el hombre es un animal inserto en tramas de significación que él mismo ha tejido, considero que la cultura es esa urdimbre y que el análisis de la cultura ha de ser por lo tanto, no una ciencia experimental en busca de leyes, sino una ciencia interpretativa en busca de significaciones. Lo que busco es la explicación, interpretando expresiones sociales que son enigmáticas en su superficie (2003: 20).

La publicidad habla a los individuos con los códigos culturales imperantes en cada momento. Son códigos impregnados de valores sociales que podríamos decir que son impuestos por las instituciones políticas, educativas, económicas. Los relatos de la publicidad muestran patrones culturales a través de experiencias aparentemente iguales entre receptores y personajes y ambientes publicitados (Curran, 1981; Mick and Buhl, 1992; Scott, 1994a; Frith, Shaw and Cheng, 2005). Sin embargo, cuando analizamos escenarios y relaciones sociales representadas en la publicidad nos damos cuenta de que se trata de un artefacto persuasivo y que, en realidad, las experiencias culturales de la mayoría de la sociedad distan mucho de las experiencias amables y opulentas de la ficción audiovisual publicitaria.

Generalmente, los individuos desean aquellos escenarios vitales o relaciones sociales que no tienen, bien porque no han tenido acceso a ellos, bien porque tuvieron acceso a ellos en algún momento y en la actualidad no pueden alcanzar. En las sociedades actuales se ha anclado un pensamiento clave que dirige gran parte de los comportamientos mayoritarios de las personas; se trata de la idea de éxito social adherida a la consecución de un estatus materializado en ciertos objetos. Dicho de otro modo, los objetos, gracias a la publicidad, dan acceso a un escenario o a un estereotipo que nos ayudan a conseguir un estatus alto virtual en la sociedad. La publicidad nos habla directamente a nosotros pero en esa pseudocomunicación también están presentes los demás, lo que piensan el resto de individuos de nuestra sociedad o nuestro grupo sobre nosotros. Tal y como argumentaba Goffman:

En la mayoría de las sociedades parece haber un sistema fundamental o general de estratificación y en la mayoría de las sociedades estratificadas existe una idealización de los estratos superiores y cierta aspiración a ascender hasta ellos por parte de los que se encuentran en situación inferior (1994: 47). 
Las personas nos encontramos en una constante comparación con el resto de individuos. Por ello, cada miembro social necesita proyectarse imaginariamente cuando ve un anuncio publicitario y observarse en pleno funcionamiento social, frente a otros que lo miran, lo analizan y lo juzgan. Se trata de influencias tan fuertes como las de la familia, amigos u otros que consiguen determinar nuestros pensamientos y nuestras conductas (Eguizábal, 2007: 127). Todos somos vulnerables a la publicidad porque es normal en tanto que el relato de la publicidad es coherente con la pauta socialmente asumida. La publicidad nos habla mediante unos códigos narrativos que representan el "sentido común", atendiendo a las consideraciones de Fiske (1987: 6).

Así que los objetos de consumo no solo son los productos y servicios que se publicitan, sino que existe un ámbito imaginario mucho más fuerte, el del relato publicitario. Los individuos comprarán o no los objetos anunciados, pero lo que consumen de manera instantánea es la ficción publicitaria. Esa narración, como ocurre con las novelas o con las películas de cine, se consume en el acto y da acceso directo al surgimiento del deseo de un estatus concreto; al deseo de vivir un ambiente o posicionarte de un modo determinado en tus relaciones sociales. En este sentido, la publicidad apuntala los valores hegemónicos y estereotipados de la cultura de las sociedades capitalistas contemporáneas.

\section{Metodología}

Teniendo en cuenta todo el marco teórico expuesto, sabemos que el objeto de estudio que nos ocupa se refiere a construcciones narrativas de carácter simbólico y, por tanto, debemos considerar el contexto histórico y social, así como el carácter institucional del relato publicitario. De modo que el examen sobre publicidad que abordamos requiere un proceso interpretativo o hermenéutico, cualitativo, a partir de unos datos concretos que obtenemos de un análisis de contenido, cuantitativo. El análisis de contenido que desplegamos está emparentado con la teoría del encuadre, ampliamente utilizada en textos televisivos de toda índole. Este método nos ayuda a extraer conclusiones interesantes para nuestro objeto de estudio, teniendo en cuenta que "la realidad que es objeto de transmisión sufre un proceso de limitación, que comienza en el momento inicial de elaboración y concluye en los efectos que se inducen en el receptor" (Sánchez Aranda y Berganza Conde, 1999: 138). En definitiva, los parámetros de medición y evaluación parten de un protocolo de análisis cuantitativo, en la selección muestral, y se concretarán en un análisis cualitativo, sobre todo en la configuración de las categorías de análisis y posterior interpretación.

La muestra de análisis está conformada por 612 unidades o espots publicitarios que han sido emitidos en las principales cadenas generalistas (La1, La2, Antena3, Cuatro, Telecinco y La Sexta) en el prime time de la noche (22 a 24 horas), desde 2009 a 2012. La selección muestral se ha realizado de manera estratégica (Wimmer y Dominick, 1996: 176-178). Así, la recogida de unidades de análisis se ha realizado 
en cuatro semanas de cada año, coincidiendo con las cuatro estaciones o épocas que marcan campañas publicitarias diferentes, ya que dependiendo de la época del año, los objetos anunciados y los existentes de los relatos son bien distintos. La selección final de unidades de análisis se ha realizado de manera aleatoria, debido al volumen de anuncios recogidos.

Para el análisis de contenido hemos seleccionado dos grandes categorías referentes a los existentes de la narración publicitaria televisiva: escenarios y personajes. A su vez, estas dos grandes categorías las hemos dividido en otras subcategorías de carácter sociocultural. Dicho de otro modo, hemos creado subcategorías o conceptos insertos en los relatos que implican un efecto potencial en la interpretación del receptor y que tienen una implicación en la forja de un pensamiento y una conducta que pueden determinar su experiencia posterior. Estas subcategorías son, para la categoría escenarios, objetos, lugares y paisajes relacionados con el momento, clima y época histórica, para los casos en los que el relato esté ambientado en otro instante que no represente el actual. Las subcategorías para la categoría personajes son rasgos físicos, carácter, conducta general que desarrollan y relaciones con otros personajes. La información resultante de las subcategorías ha sido interpretada atendiendo exclusivamente a la clase social representada. Y con toda esa información hemos desarrollado el análisis discursivo, fundamentado en una perspectiva crítica de la cultura, como hemos esbozado en el epígrafe anterior.

\section{Resultados y discusión. Cronotopos y estereotipos, recursos narrativos para la identificación}

Los resultados cuantitativos de la investigación objetivan una presencia mayoritaria de escenarios y personajes cargados de lujo. La mayoría de relatos publicitarios comunican cronotopos y estereotipos inundados de riqueza. Así, el 73\% de los anuncios televisivos analizados utilizan escenarios opulentos y ostentosos. Por otro lado, el $67 \%$ de espots analizados representa personajes y relaciones sociales en las que el vínculo de unión es el gusto, deseo o alabanza a un estatus de clase media-alta o alta. Todo ello nos lleva a interpretar, siguiendo la pauta teórica que hemos propuesto, que los receptores están potencialmente predispuestos a consumir ambientes y relaciones sociales de ficciones publicitarias en las que el valor principal es el de escalar económicamente en los estratos imaginarios de la sociedad. Las categorías estudiadas transmiten mayoritariamente estos valores, que son los rasgos axiológicos que definen el eje psicológico de las narraciones de la publicidad; lo que supone una determinación interpretativa que está inserta en el texto persuasivo. Ello, consecuentemente, conlleva un límite en el proceso de identificación del receptor frente a escenarios y personajes. No obstante, a partir del momento de recepción, en el caso de que el proceso de comunicación haya tenido éxito, el receptor siente un fuerte deseo de estar allí, en ese escenario y en ese momento, siendo ese personaje y disfrutando de esas fructíferas relaciones. 
¿Por qué surge ese deseo tan intenso simplemente con la exposición a un relato audiovisual? Como podemos comprobar a partir de la investigación, porque la publicidad es precisamente una ficción que representa modos de vida posibles. Digamos que la argumentación publicitaria presenta premisas y conclusiones plausibles en sus relatos sobre escenarios o cronotopos y personajes o estereotipos cuya realidad o materialidad es posible pero no están presentes habitualmente en nuestro día a día.

Para comprender mejor este proceso, podríamos hacer una comparación entre dos representaciones de mujer, una que está presente habitualmente en nuestra cotidianidad y otra que está presente en ocasiones en los relatos publicitarios. Una representación de mujer en el primer sentido puede ser el dibujo que se coloca en la puerta de los baños para indicar que ese es el lugar de las chicas y se diferencia del lugar habilitado a los chicos. Se trata únicamente de una silueta convencional y que representa a la mujer. La otra representación de mujer podría ser Angelina Jolie como personaje de un relato publicitario. Esta recreación de la mujer lleva adheridos un ambiente y un estereotipo y, además, consigue generar deseo, tanto a los hombres como a las mujeres. A los primeros seguramente porque estarían encantados de compartir sus vidas con este personaje estereotipado. A las segundas porque les encantaría ser ella y poder desenvolverse en ese cronotopo específico; asumiendo el concepto de cronotopo que utiliza Bajtín (1994) para analizar el hecho cultural literario. En este sentido, el cronotopo publicitario describe el modo en el que las configuraciones del tiempo y del espacio son representados en el relato. Son escenarios compuestos por objetos, lugares o paisajes que se relacionan con un momento determinado y que aportan visiones específicas del mundo y una ideología o pauta cultural concreta. Bajtín (1994: 84-258) da el nombre de cronotopo a una conexión intrínseca que es producida por relaciones temporales y espaciales que se expresan artísticamente en la literatura. En el cronotopo artístico literario existen unos indicadores espaciales y temporales que se unen para dar lugar a una unidad concreta. Por decirlo de un modo simple, el tiempo se materializa o se hace visible a la interpretación de los individuos. Igualmente, el espacio está subordinado al tiempo, a la trama. De tal forma que el cronotopo llega a determinar en gran medida la imagen del hombre a través de los personajes y de los escenarios seleccionados.

Sánchez Noriega nos muestra que un cronotopo es "un espacio/tiempo singular que adquiere protagonismo en la estructura narrativa de un relato y hasta llega a configurar un género, como el castillo de la novela gótica, los suburbios del cine negro, el camino de las narraciones de aventuras, el desierto del western" (2006: 54). Estos escenarios propuestos por los discursos audiovisuales como el de la publicidad guían la interpretación del receptor hacia el deseo de esa categoría.

Ocurre con los personajes y con sus relaciones (entre ellos y con el ambiente). Junto al escenario o escenarios presentes en el relato, constituyen los existentes de toda narración audiovisual y, por tanto, son el epicentro de la interpretación potencial. "Todo personaje viene definido por su ser (identidad, rasgos físicos, carácter...) y por su hacer, por la conducta que desarrolla y por las relaciones que establece con 
otros personajes, lo que supone una serie de rasgos que lo individualizan (Sánchez Noriega, 2006: 53). El receptor generalmente descodifica toda la información que transmiten los personajes a través de sus acciones y de sus relaciones. Esos datos guían las impresiones de los individuos y, en publicidad, desarrollan el deseo, el querer estar ahí y vivir la vida de los personajes representados. Porque todo receptor de comunicación mediática se percibe a sí mismo como individuo que ve una ficción. Sin embargo, se identifica con ella, bien sea con el malo del relato o con el bueno. Con el héroe o con el desgraciado. Con el ambiente basado en el estilo de vida americano o con los escenarios costumbristas de nuestro entorno. Este proceso de identificación se debe a que "el espectador ha de ser crédulo en el mundo de ficción para mantener la ilusión cinematográfica [y para mantener la ilusión publicitaria, añadimos] al mismo tiempo que sabe que los hechos representados son ficcionales; es decir, su conciencia se encuentra escindida entre la creencia y el conocimiento" (Sánchez Noriega, 2006: 90).

Consecuentemente, cronotopo y estereotipo de la publicidad se configuran en una relación que da lugar a formas de experiencia que el receptor desea porque no forman parte de su vida en ese momento, pero pueden hacerlo potencialmente. Un anuncio de Mercedes transmitido a través de escenarios y personajes que se relacionan en el ámbito del lujo es objeto de deseo de la mayoría de los espectadores. Esto se debe a que hay muchos individuos que no experimentan vidas rodeadas de tanto lujo como las que se muestran en el espot. Pero también porque existen unos pocos receptores que sí experimentan dicho ambiente y desean mantenerlo con el nuevo Mercedes.

Este proceso que acabamos de explicar se lleva a cabo porque cronotopo y estereotipos nos informan sobre la clase social en la que se sitúa el objeto publicitado; el ámbito humano que el receptor debe anhelar. No obstante, la ficción publicitaria es un elemento narrativo causal, que da lugar a una determinada descodificación por parte de la audiencia, tomando como referencia los límites significativos que se proponen en el relato y que siempre presentan un carácter cultural e ideológico y, por tanto, normativo (Scott, 1994b; McQuarrie y Mick, 1999). No queremos decir con ello que los individuos no participen en el acto de descodificación, o que lo hagan de una manera secundaria. El receptor es actor principal en el proceso de interpretación y genera sus propias conclusiones sobre lo que percibe. Sin embargo, aunque la mayoría de receptores sean activos y reconstruyan por sí mismos el relato que perciben, lo hacen a partir de unos esquemas y directrices que les ofrece el mismo relato (Bordwell, 1996).

Por todo ello, la aparente distancia que se le plantea al receptor frente a los escenarios y personajes publicitados se torna cercanía, ya que se trata de expresiones culturales e ideológicas que debe seguir para mantenerse en el flujo de relaciones que impone la sociedad. El receptor no se conforma con su vida, sino que anhela la que se publicita, que es una vida mucho mejor. El ser humano prefiere soñar experiencias positivas por venir y no pensar continuamente que su vida va a ser siempre igual de monótona e insignificante. 


\section{Conclusiones}

El relato publicitario es un artefacto legitimado por empresas e instituciones que sigue una pauta ideológica afín al pensamiento y al comportamiento hegemónicos de la sociedad del momento. Su objetivo es conectar con los públicos mediante el mecanismo de la identificación. A través del movimiento representativo de la ficción publicitaria, los individuos generan potencialmente experiencias oníricas de una vida mejor. La publicidad conecta con una audiencia heterogénea por medio de una narración audiovisual en la que el epicentro del proceso de identificación lo conforman los escenarios o ambientes, los personajes y las relaciones sociales representadas. Estos existentes de la narración actúan como garantes de un futuro mejor; pero, como sabemos, los futuros no llegan al estar siempre alejados de los presentes. Precisamente por ello, como el burro que persigue la zanahoria, la mayoría de receptores busca continuamente estar ahí, anhela una vida de ficción. Las motivaciones a las que da lugar la publicidad se cimentan en representaciones de experiencias vitales que llegan a convertirse en esperanzas de vidas por llegar. Vidas posibles, solo accesibles simbólicamente mediante la adquisición del objeto publicitado.

Las personas desean notoriedad. Quieren escribir su nombre en la barra de búsqueda de Google y que la primera entrada que aparezca sea la referente a ellas. Las personas adaptadas a las dinámicas de socialización actuales buscan un me gusta de Facebook para sus experiencias vitales o un retuiteo de sus vivencias. El universo de ficción que plantea la publicidad, organizado narrativamente por medio de cronotopos y personajes estereotipados, ofrece al individuo un vehículo para posicionarse socialmente en un estadio superior en el escalafón simbólico de clases. La publicidad ofrece al receptor un medio de transmisión de un estatus imaginado que se materializa en los objetos que se publicitan.

\section{Bibliografía}

AAKER, D. A., BARTRA, R. and MYERS, J. G. (1996). Advertising Management. Upper Saddle River, NJ: Prentice Hall.

BAJTIN, M. M. (1994). The Dialogic Imagination: Four Essays. Austin: University of Texas Press.

BORDWELL, D. (1996). La narración en el cine de ficción. Barcelona: Paidós.

CURRAN, J. (1981). "The Impact of Advertising on the British Mass Media". En: Media, Culture and Society, $\mathrm{n}^{\circ}$ 3. p. 43-69.

EGUIZÁBAL, R. (2007). Teoría de la publicidad. Madrid: Cátedra.

FISKE, J. (1999). Television Culture. London: Routledge.

FRITH, K., SHAW, P. and CHENG, H. (2005). "The Construction of Beauty: A Cross-Cultural Analysis of Women's Magazine Advertising". En: Journal of Communication, vol. 55, $\mathrm{n}^{\mathrm{o}}$ 1. p. 56-70.

GEERTZ, C. (2003). La interpretación de las culturas. Barcelona: Gedisa. 
GOFFMAN, E. (1994). La presentación de la persona en la vida cotidiana. Buenos Aires: Amorrortu.

HARRIS, M. (2007). Introducción a la antropología general. Madrid: Alianza.

HIRSCHMAN, E. C. (2003). "Men, Dogs, Guns, and Cars. The Semiotics of Rugged Individualism". En: Journal of Advertising, vol. 32, nº 1. p. 9-22.

JHALLY, S. (1987). The Codes of Advertising. Fetichism and the Political Economy of Meaning in the Consumer Society. London: Frances Printer.

KATES, S. M. and SHAW-GARLOCK, G. (1999). "The Ever Entangling Web: A Study of Ideologies and Discourses in Advertising to Women". En: Journal of Advertising, vol. 28, $\mathrm{n}^{\circ}$ 2. p. 33-49.

LIN, C. A. (2001). "Cultural Values Reflected in Chinese and American Television Advertising". En: Journal of Advertising, vol. 30, no 4. p. 83-94.

LULL, J. (2009). Media, Communication, Culture: A Global Approach. New York: Columbia University Press.

McQUARRIE, E. F. y MICK, D. G. (1999): "Visual Rhetoric in Advertising: Text-Interpretive, Experimental, and Reader-Response Analyses". En: Journal of Consumer Research, vol. 26, $\mathrm{n}^{\circ}$ 1. p. 37-54.

McROBBIE, A. (1994). Postmodernism and Popular Culture. London: Routledge.

MICK, D. G. and BUHL, C. (1992). "A Meaning-based Model of Advertising Experiences". En: Journal of Consumer Research, vol. 19, n 3. p. 317-338.

MORLEY, D. (1998). "So-called cultural studies: dead ends and reinvented wheels". En: Cultural Studies, vol. 12, n 4. p. 476-497.

POLLAY, R. W. and GALLAGHER, K. (1990). "Advertising and Cultural Values: Reflections in the Distorted Mirror". En: Journal of International Advertising, vol. 9. p. 359-372.

RUSSELL, T. J. and LANE, R. W. (2005). Kleppner publicidad. Mexico: Prentice Hall.

SÁNCHEZ ARANDA, J. J. y BERGANZA CONDE, M. R. (1999): "Framing en la prensa española: la información sobre la muerte y funeral de Diana de Gales". En: Comunicación y Sociedad, vol. XII, nº 1. p. 137-161.

SÁNCHEZ NORIEGA, J. L. (2006). Historia del cine. Teorias y géneros cinematográficos, fotografia y televisión. Madrid: Alianza.

SAN NICOLÁS, C. (2003). Aspectos de comunicación y creatividad publicitarias. Murcia: UCAM.

SCOTT, L. M. (1994a). "Images in Advertising: The Need for a Theory of Visual Rhetoric". En: Journal of Consumer Research, vol. 21, $\mathrm{n}^{\circ}$ 2. p. 252-273.

SCOTT, L. M. (1994b): "The Bridge from Text to Mind: Adapting Reader Response Theory to Consumer Research". En: Journal of Consumer Research, vol. 21. p. 461-480.

WERNICK, A. (1983). "Advertising and Ideology: An Interpretative Framework". En: Theory, Culture and Society, vol. 2, n⿳ 1. p. 16-33.

WERNICK, A. (1994). Promotional Culture: Advertising, Ideology and Symbolic Expression. London: Sage. 
WILLIAMS, R. (1993). “Advertising: the magic system”. En: During, S. (ed.). The Cultural Studies Reader. London: Routledge. p. 320-336.

WIMMER, R. D. y DOMINICK, J. R. (1996). La investigación científica de los medios de comunicación. Una introducción a sus métodos. Barcelona: Bosch.

\section{Los autores}

Javier García López es Profesor Adjunto en la Universidad a Distancia de Madrid, donde imparte las asignaturas "Teoría de la Publicidad", "Opinión Pública" e "Historia de la Comunicación Social". Anteriormente ha sido profesor en la Universidad San Jorge de Zaragoza, en el área de Publicidad. Obtuvo el doctorado en Comunicación y la licenciatura en Publicidad. Es autor de diversos artículos científicos, capítulos de libro y monografías. Es especialista en Epistemología y Gnoseología, así como en Comunicación Institucional y de la Empresa.

Pedro Ant. Hellín Ortuño es Profesor Titular en la Universidad de Murcia y Vicedecano del Grado de Publicidad y Relaciones Públicas de la Facultad de Comunicación y Documentación, donde imparte "Discurso Publicitario" y "Publicidad y Cultura de Masas". Ha sido profesor invitado en los programas de postgrado de varias universidades de Europa y América y pertenece al Grupo de Investigación GESC3 de la Universidade de Sao Paulo, con quien desarrolla el Estudio Mundial de Tendencias para IPSOS. 